\title{
Microscopy Investigation of Surface Contamination Effect on Fatigue Fracture of Al60 (Glidcop) Wire
}

\author{
RE Goddard $^{1 *}$ and VJ Toplosky ${ }^{1}$ \\ 1. National High Magnetic Field Laboratory, Florida State University, Tallahassee, FL, USA. \\ *Corresponding author: goddard@magnet.fsu.edu
}

GlidCop is a generic commercial name for copper strengthened with $\mathrm{Al}_{2} \mathrm{O}_{3}$ dispersed nano-particles. Al60 is GlidCop that contains 1.1 weight percent $\mathrm{Al}_{2} \mathrm{O}_{3}$ while maintaining excellent electrical conductivity and tensile strength in drawn wire of approximately $560 \mathrm{MPa}$ at room temperature. This makes the material ideal for high-field pulsed magnets that are useful in determining the behavior of matter. In winding these magnets, drawn wire can be deformed to 30 percent [1] or more. When the magnet is energized the strain is increased even more. The magnetic field generated can be on the order of 100 Teslas.

While spooling $5.2 \mathrm{~mm}$ X $8.6 \mathrm{~mm}$ Al60 conductor wire prior to magnet winding, inclusions were noticed embedded into the wire's surface (Fig. 1). Foreign particles, especially in the interior, can be detrimental to the performance of the wire under stress. Premature fatigue crack initiation may develop due to persistent slip bands radiating from a stress concentration [2]. To determine the effect, if any, of the surface impurities, fatigue tests were conducted and the fracture surfaces were analyzed [3]. Fatigue test samples were machined from the lengths of conductor that contained the inclusions. Eight samples with a reduced cross section $(2.5 \mathrm{~mm}$ X $5.2 \mathrm{~mm})$ were tested (Fig. 2).

Test samples 1, 4, 6, and 8 broke irregularly at or near the radial/gauge length transition (Fig. 2). The cycle-versus-stress curves generated from these samples indicated a rapid transition from tensile to compressive loading (although strain amplitude remained constant). This induced a bending moment due to sample misalignment as opposed to the more desirable uniaxial loading. The results are therefore considered invalid. Of the remaining samples where no bending was observed during testing, the crack initiation always started at surface inclusions (Fig. 3). The inclusions in all instances are primarily iron with some iron oxide (Fig. 4). It is believed that the inclusions had been introduced during the drawing process by the foreign material, which were embedded and then pressed into the wire by the drawing through the dies (Fig. 5). The iron inclusion in sample 2 was lost prior to test but left an indent where the crack initiation started and bisected it (Fig. 6). The crack still initiated at this stress concentration of missing wire material created by the iron inclusion and the strained microstructure of the underlying wire. The approximate size and depth of penetration versus the number of fatigue cycles is given by Table 1. The surface inclusions do affect the service life of this high-strength wire and should be processed in a clean environment to reduce the risk of introducing surface impurities. Due to the irregularities of size and shape a direct quantitative correlation cannot be deduced. The work has been supported by NSF and the State of Florida [4].

\section{References:}

[1] RE Goddard, KH Han and DN Nguyen, Microsc. Microanal. (2016), p. 1992. 
[2] H Mughrabi, Phil. Trans. R. Soc. A 373 (2015). http://doi.org/10.1098/rsta.2014.0132 (Accessed February 4, 2019)

[3] K Han et al., IEEE Trans. Appl. Supercond., 20 (3) (2010), p. 1463.

[4] The work was undertaken in the National High Magnetic Field Laboratory, which is supported by NSF DMR-1157490 and the State of Florida.

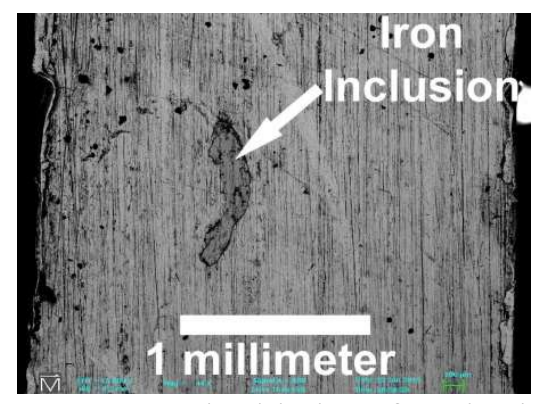

Figure 1. Embedded surface inclusion (SEM Micrograph).

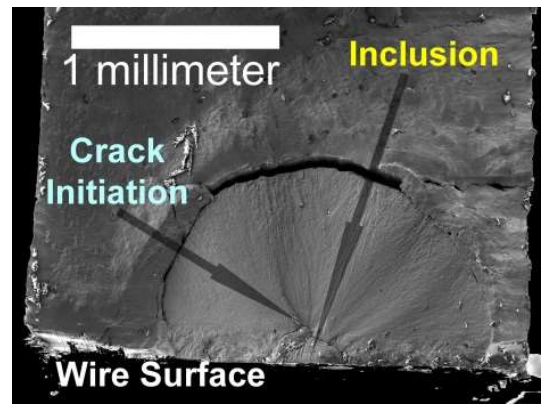

Figure 3. Fatigue fracture surface (SEM micrograph).

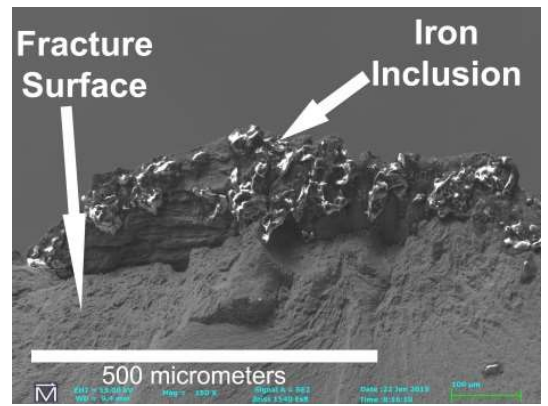

Figure 5. Inclusion view from fracture surface (SEM micrograph).

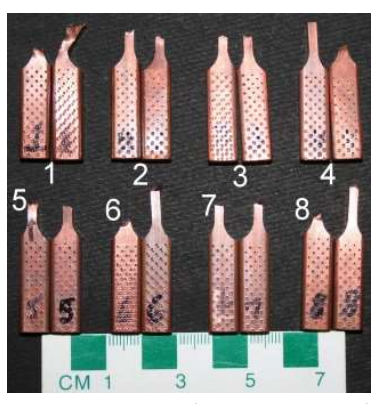

Figure 2. Fatigue samples.

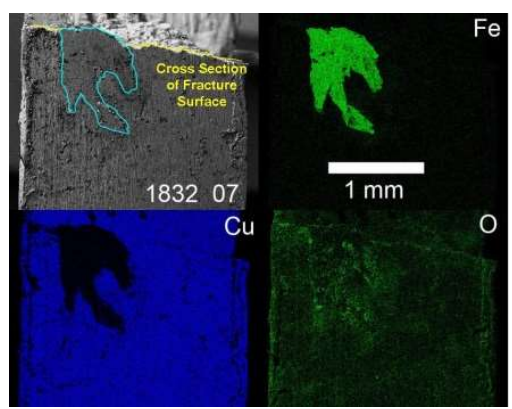

Figure 4. Elemental x-ray map of wire with surface inclusion.

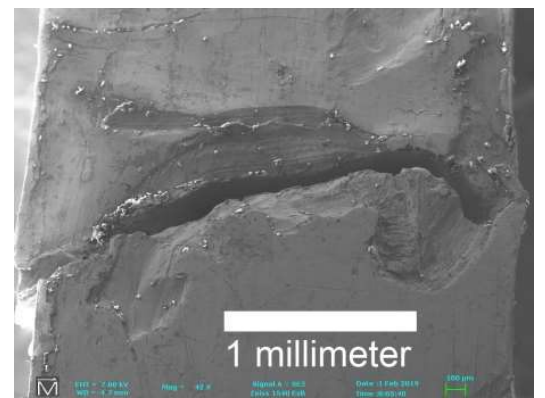

Figure 6. Fatigue fracture bisecting void left by inclusion (SEM micrograph).

\begin{tabular}{|c|c|c|c|}
\hline Sample & Fatigue Cycle to Failure & $\begin{array}{c}\text { Maximum Depth } \\
\text { (micrometers) }\end{array}$ & $\begin{array}{c}\text { Volume (cubic } \\
\text { micrometers) }\end{array}$ \\
\hline 2 & 6159 & 120 & $5.88 \times 10^{7}$ \\
\hline 3 & 189477 & 100 & $3.48 \times 10^{7}$ \\
\hline 5 & 25254 & 178 & $0.60 \times 10^{7}$ \\
\hline 7 & 39605 & 88 & $2.21 \times 10^{7}$ \\
\hline
\end{tabular}

Table 1. Fatigue cycle failure versus sample dimensions. 